\section{(6) OPEN ACCESS}

\title{
Greenness and allergies: evidence of differential associations in two areas in Germany
}

\author{
Elaine Fuertes, ${ }^{1,2}$ lana Markevych, ${ }^{1,3}$ Andrea von Berg, ${ }^{4}$ Carl-Peter Bauer, ${ }^{5}$ \\ Dietrich Berdel, ${ }^{4}$ Sibylle Koletzko, ${ }^{6}$ Dorothea Sugiri, ${ }^{7}$ Joachim Heinrich ${ }^{1}$
}

- Additional material is

published online only. To view please visit the journal online (http://dx.doi.org/10.1136/jech2014-203903).

For numbered affiliations see end of article.

\section{Correspondence to} Joachim Heinrich, Institute of Epidemiology I, Helmholtz Zentrum München, German Research Centre for Environmental Health, Ingolstädter Landstr. 1, Neuherberg 85764, Germany; heinrich@helmholtz-muenchen. de

Received 23 January 2014 Revised 23 April 2014 Accepted 9 May 2014 Published Online First 26 May 2014
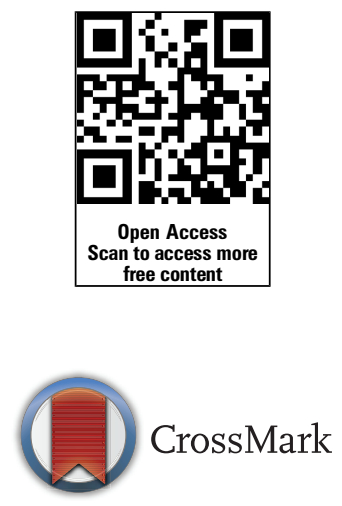

To cite: Fuertes $\mathrm{E}$, Markevych I, von Berg A et al. J Epidemiol Community Health 2014;68:787-790.

\section{ABSTRACT}

Background Positive greenness effects on health are increasingly reported, although studies on allergic outcomes remain limited and conflicting. We examined whether residential greenness is associated with childhood doctor diagnosed allergic rhinitis, eyes and nose symptoms and aeroallergen sensitisation using two combined birth cohorts (GINIplus and LISAplus) followed from birth to 10 years in northern and southern Germany $\left(N_{\text {total }}=5803\right)$.

Methods Mean residential greenness in a $500 \mathrm{~m}$ buffer around the 10-year home addresses was defined using the Normalized Difference Vegetation Index, a green biomass density indicator. Longitudinal associations were assessed per study area (GINI/LISA South and GINI/LISA North) using generalised estimation equations adjusted for host and environmental covariates.

Results Despite identical study designs and statistical modelling, greenness effects differed across the two study areas. Associations were elevated for allergic rhinitis and eyes and nose symptoms in the urban GINI/LISA South area. In contrast, risk estimates were significantly below one for these outcomes and aeroallergen sensitisation in rural GINI/LISA North. Area-specific associations were similar across buffer sizes and addresses (birth and 6 years) and remained heterogeneous after air pollution and population density stratification.

Conclusions Existing and future single-area studies on greenness and green spaces should be interpreted with caution.

\section{INTRODUCTION}

Recent studies generally indicate a beneficial relationship between green spaces and greenness and health outcomes. ${ }^{1-6}$ The evidence for allergies, however, remains limited and conflicting. ${ }^{7}$ The green environment may protect against allergies by increasing exposure to a greater number and diversity of microbes via mechanisms encompassed by the hygiene ${ }^{9}$ and biodiversity ${ }^{10}$ hypotheses, by encouraging outdoor play and by improving local air quality. However, the green environment is also a source of allergens, which may exacerbate allergic responses in themselves and via interactions with air pollutants. ${ }^{11}$

Using the "German Infant study on the influence of Nutrition Intervention plus environmental and genetic influences on allergy development" (GINIplus) and the "influence of Life-style factors on the development of the Immune System and Allergies in East and West Germany plus the influence of traffic emission and genetics" (LISAplus) prospective birth cohorts, we examined whether greenness around the home address was associated with allergic outcomes from 3 to 10 years in two areas in Germany. Associations were stratified by traffic-related air pollution levels, population density and parental education, as green effects on health may vary by urbanisation and socioeconomic status. $^{35}$

\section{METHODS}

As the GINIplus and LISAplus birth cohorts have nearly identical study designs, data were pooled and are presented per study area (GINI/LISA South and GINI/LISA North). The Leipzig and Bad Honnef study areas were excluded as address information was not available. GINI/LISA South covers the urban city of Munich, Germany, and its surrounding areas (approximately $28000 \mathrm{~km}^{2}$ ). GINI/ LISA North covers the rural area near the industrial Ruhr area in Germany (approximately 12000 $\mathrm{km}^{2}$ ). Local Ethics Committees approved both studies, and written consent was obtained from parents of participants.

Three longitudinal outcomes derived from parentcompleted questionnaires, as previously described, ${ }^{12}$ were included in this analysis: doctor diagnosis of allergic rhinitis (yearly, from 3 to 10 years), eyes and nose symptoms (at 4, 6 and 10 years) and aeroallergen sensitisation (at 6 and 10 years).

The Normalized Difference Vegetation Index (NDVI), a green biomass density indicator, was used as a surrogate for surrounding greenness. Its calculation is based on the difference of surface reflectance in visible $(0.4-0.7 \mu \mathrm{m})$ and nearinfrared $(0.7-1.1 \mu \mathrm{m})$ wavelengths. Values range from negative one (water) through zero (rock, sand, snow) to positive one (dense green vegetation). ${ }^{13}$ The assignment of NDVI to the home addresses of GINI/LISA South participants has been previously described (using two cloud-free satellite images from 14 July 2003 and one from 24 August 2003). ${ }^{4}$ The same procedure was used for GINI/ LISA North (using one cloud-free satellite image from 10 July 2003). Using these values, mean greenness in circular 500,800, 1000 and $3000 \mathrm{~m}$ buffers around the birth, 6- and 10-year participant addresses were calculated, as distance to greenness may be important. ${ }^{14}$ The spatial distribution of mean greenness in the $500 \mathrm{~m}$ buffer around the 10-year home addresses is provided (see online supplementary material, figure $\mathrm{S} 1$ ).

Longitudinal associations between mean greenness and the health outcome prevalences were analysed using generalised estimation equations (logit link and exchangeable correlation structure). 
Models were adjusted for age, sex, parental history of atopy, older siblings, maternal smoking during pregnancy, tobacco smoke exposure in the home (birth-4 years), cohort (GINIplus observation arm/GINIplus intervention arm/LISAplus) and parental education (highest number of years of education of either parent: $<10$ years, $=10$ years and $>10$ years).

Estimated concentrations of nitrogen dioxide $\left(\mathrm{NO}_{2}\right)$ and particulate matter with aerodynamic diameters less than $2.5 \mu \mathrm{g} / \mathrm{m}^{3}$ $\left(\mathrm{PM}_{2.5}\right.$ mass), common measures of traffic-related air pollution, were derived from land-use regression models ${ }^{15-18}$ for the birth, 6- and 10 -year addresses of participants. ${ }^{12}$ Population density in $5000 \mathrm{~m}$ buffers were obtained from the WiGeoGIS raster dataset with a spatial resolution of $125 \mathrm{~m}$ for 2008 and used as a proxy for urbanisation. Associations with NDVI were examined per area-specific $\mathrm{NO}_{2}, \mathrm{PM}_{2.5}$ mass and population density tertiles. NDVI calculations were performed in ArcGIS 10.0 Geographical Information System (ESRI, Redlands, California, USA) and Geospatial Modelling Environment (Spatial Ecology LLC), and statistical analyses in R, V.2.13.1 (http://www. R-project.org).

\section{RESULTS}

Health and NDVI data for at least one time point were available for 3306 children in GINI/LISA South and 2497 children in GINI/LISA North. The areas differed with respect to several population characteristics (see online supplementary material, table S1). For all buffers, surrounding greenness was lower for GINI/LISA South than GINI/LISA North (mean NDVI $=0.35$ (range $0.08-0.65)$ and $0.43(0.18-0.65)$ for the $500 \mathrm{~m}$ buffer around the 10-year home addresses, respectively), and highly correlated across buffers and addresses (in combined population, Pearson's correlation >0.7). Mean $\mathrm{NO}_{2}$ and $\mathrm{PM}_{2.5}$ mass concentrations at the 10-year addresses were lower in GINI/LISA South (19.8 and $13.3 \mu \mathrm{g} / \mathrm{m}^{3}$, respectively) than GINI/LISA North (23.7 and $17.4 \mu \mathrm{g} / \mathrm{m}^{3}$, respectively).

Risk estimates for mean greenness in a $500 \mathrm{~m}$ buffer around the 10-year home address were elevated for doctor diagnosed allergic rhinitis and eyes and nose symptoms in GINI/LISA South (table 1). In contrast, estimates for GINI/LISA North were significantly below one for all outcomes. Associations were similar when stratified by indoor and outdoor aeroallergens. Adjustments for early-life farm and pet exposure slightly attenuated associations in GINI/LISA North only. Risk estimates were consistent across buffer sizes but generally not significant for the $3000 \mathrm{~m}$ buffer. Results were similar for greenness assessed at birth, 6- and 10-year addresses, especially for GINI/LISA North, but strongest at the latest address. Risk estimates for NDVI at the birth address appeared slightly stronger among those who never moved between birth and 10 years, although results were inconsistent across outcomes.
Associations stratified by area-specific $\mathrm{PM}_{2.5}$ mass, $\mathrm{NO}_{2}$ and population density tertiles were inconsistent across study areas (figure 1). In GINI/LISA South, risk estimates increased from null to significantly elevated with increasing $\mathrm{PM}_{2.5}$ mass tertiles. For GINI/LISA North, risk estimates increased with increasing $\mathrm{PM}_{2.5}$ mass and population density tertiles, but from significantly protective to null. Risk estimates were significantly below one in the lowest $\mathrm{NO}_{2}$ strata for this area.

\section{DISCUSSION}

Residential greenness was differentially associated with allergic outcomes up to 10 years among children living in two areas in Germany. In the urban GINI/LISA South area, greenness appeared positively associated with allergic rhinitis and eyes and nose symptoms. In contrast, greenness was negatively associated with these outcomes and aeroallergen sensitisation in the rural GINI/LISA North area.

Model adjustments for altitude, population density, individual-level socioeconomic status and air pollution were unable to explain the contrasting trends. We thus hypothesise that differences in greenness types (vegetation), which cannot be distinguished using NDVI values, may account for some risk estimate heterogeneity. Greenness in GINI/LISA South, a predominantly urban area, is likely more seminatural or artificial and possibly of higher allergenicity (because of lower biodiversity, introduction of exotic species, botanical sexism, etc, as described in Ref. 19). The positive associations for GINI/LISA South agree with this speculation. Furthermore, effects were strongest in areas with high $\mathrm{PM}_{2.5}$ mass concentrations, which is consistent with the hypothesis that air pollutants may increase pollen allergenicity. ${ }^{11}$ In contrast, the greenness in GINI/LISA North is more natural and agricultural, which may protect against allergy development. ${ }^{10}$ The negative associations observed for GINI/LISA North agree with this hypothesis. Furthermore, the protective effects of increasing greenness were strongest in areas with lower air pollution and population density, which are likely the areas least affected by urbanisation. However, these proposed explanations remain hypotheses that require confirmation. Indeed, NDVI effects may be mediated by several other possible mechanisms, such as access to areas for physical activity, stress reduction and improvement of positive social interactions and mental health. ${ }^{20}$

Greenness was objectively estimated using a standardised protocol to participants' home addresses implicitly assuming that a smaller distance to greenness represents a greater aeroallergen exposure. This assessment captured both large and small-scale green spaces, but did not allow vegetation types and allergenic potential to be determined. Further, 'blueness' effects could not be examined as very few children resided within $500 \mathrm{~m}$ of water. Data on greenness accessibility, time spent

Table 1 Total and area-specific associations between mean greenness in a $500 \mathrm{~m}$ buffer around the home address at 10 years and health outcomes during the first 10 years of life*

\begin{tabular}{|c|c|c|c|c|c|c|}
\hline & \multicolumn{2}{|c|}{ Total Population } & \multicolumn{2}{|c|}{ GINI/LISA South } & \multicolumn{2}{|c|}{ GINI/LISA North } \\
\hline & $\mathrm{N}$ & OR $(95 \% \mathrm{Cl})$ & $\mathbf{N}$ & OR $(95 \% \mathrm{Cl})$ & $\mathbf{N}$ & OR $(95 \% \mathrm{Cl})$ \\
\hline Allergic rhinitis & 4538 & $1.03(0.89$ to 1.19$)$ & 2531 & $1.16(0.99$ to 1.36$)$ & 2007 & 0.75 (0.60 to 0.93$)$ \\
\hline Eyes and nose symptoms & 4538 & $1.00(0.88$ to 1.14$)$ & 2530 & $1.15(1.01$ to 1.31$)$ & 2008 & 0.71 (0.56 to 0.89 ) \\
\hline Aeroallergen sensitisation & 2799 & $0.96(0.85$ to 1.07$)$ & 1669 & $1.06(0.94$ to 1.20$)$ & 1130 & 0.78 (0.65 to 0.94$)$ \\
\hline
\end{tabular}



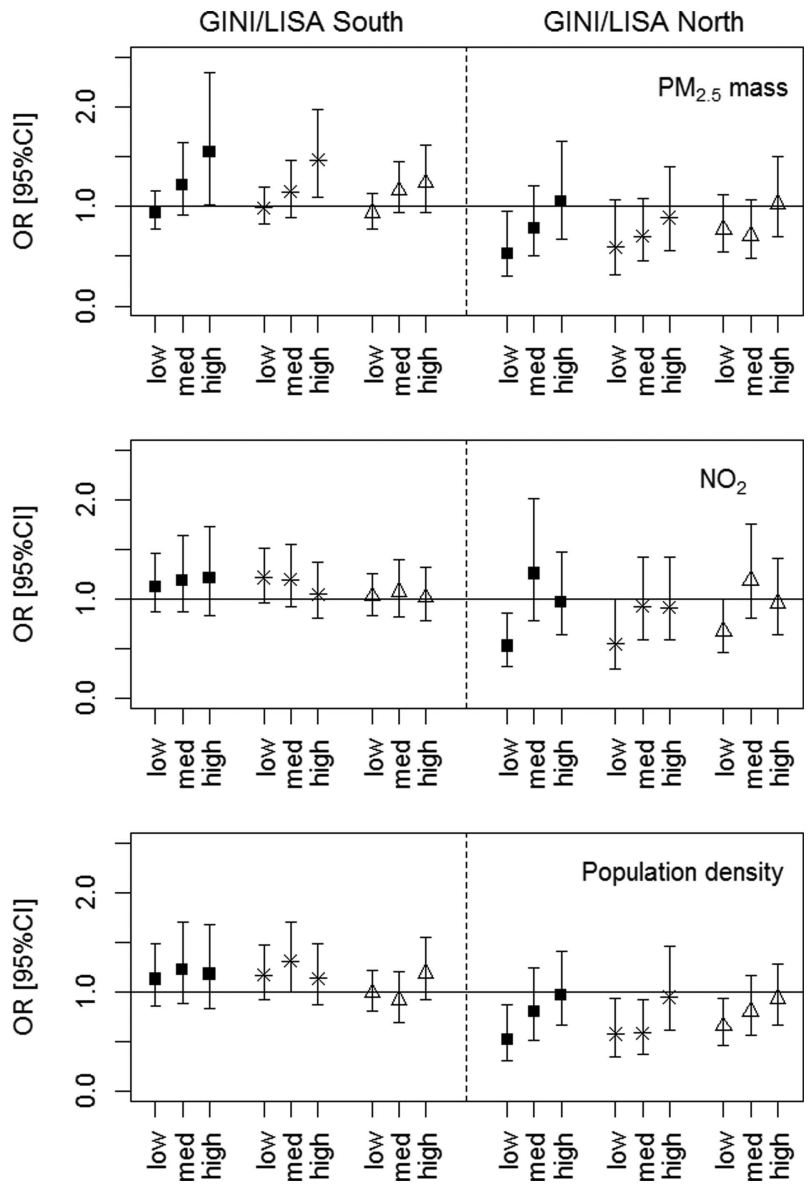

Figure 1 Area-specific associations between greenness in a $500 \mathrm{~m}$ buffer around the 10-year home address and doctor diagnosed allergic rhinitis (squares), eyes and nose symptoms (stars) and aeroallergen sensitisation (triangles) up to 10 years of age stratified by area-specific $\mathrm{PM}_{2.5}$ mass, $\mathrm{NO}_{2}$ and population density tertiles. Models are adjusted for age, sex, parental history of atopy, older siblings, maternal smoking during pregnancy, tobacco smoke exposure in the home (1-4 years), parental education and cohort. ORs and $95 \% \mathrm{Cls}$ are presented per IQR increase in greenness exposure.

outdoors, indoor greenness and greenness around schools were also not available. However, associations were similar for greenness assessed at the birth, 6- and 10-year home addresses, especially for GINI/LISA North, and when alternative cloud-free days were used to assign NDVI estimates.

This study is large, although statistical power may be limited for the stratified analyses. Identical protocols were used during the longitudinal, prospective assessment of health outcomes and area-specific associations were consistent across outcomes, one of which was objectively measured. Although several covariates were considered, residual confounding remains possible. For example, although models were adjusted for parental education as a marker of socioeconomic status, we cannot rule out the possibility that further residual confounding by socioeconomic status, both at the individual and area levels, may be affecting the results. However, any potential confounder would have to be differently associated with greenness and allergic outcomes across the study areas.

The heterogeneous associations observed across study areas are the most important results of this study. Caution is warranted when interpreting existing and future single-area epidemiological investigations. Studies varying in geography, urbanisation, vegetation types, air quality and populations are required.

\section{What is already known on this subject}

Greenness and green spaces are increasingly associated with several measures of improved health. However, epidemiological investigations on allergic health outcomes are few and conflicting. Additional prospective, longitudinal studies are required to further clarify the role of green environment proximity on allergies.

\section{What this study adds}

Despite the use of identical study designs and statistical modelling, heterogeneous associations between greenness with allergic rhinitis were observed in two study areas in Germany. These observations further emphasise that the effect of greenness and health is complex and multifaceted, and needs to be examined across studies that vary in geography, urbanisation, vegetation types, air quality and populations.

\section{Author affiliations}

${ }^{1}$ Institute of Epidemiology I, Helmholtz Zentrum München, German Research Centre for Environmental Health, Neuherberg, Germany

${ }^{2}$ School of Population and Public Health, University of British Columbia, Vancouver, British Columbia, Canada

${ }^{3}$ Division of Metabolic and Nutritional Medicine, Dr von Hauner Children's Hospital, Ludwig-Maximilians-University of Munich, Munich, Germany

${ }^{4}$ Department of Pediatrics, Marien-Hospital Wesel, Wesel, Germany

${ }^{5}$ Department of Pediatrics, Technical University of Munich, Munich, Germany

${ }^{6}$ Division of Paediatric Gastroenterology and Hepatology, Dr. von Hauner Children's Hospital, Ludwig-Maximilians-University of Munich, Munich, Germany

${ }^{7}$ IUF_Leibniz Research Institute for Environmental Medicine, University of Düsseldorf, Düsseldorf, Germany

Acknowledgements GINIplus study group: Helmholtz Zentrum München, German Research Center for Environmental Health, Institute of Epidemiology, GINI/LISA South (Heinrich J, Wichmann HE, Sausenthaler S, Zutavern A, Chen CM, Schnappinger M, Rzehak P); Department of Pediatrics, Marien-Hospital, GINI/LISA North (Berdel D, von Berg A, Beckmann C, Groß I); Department of Pediatrics, Ludwig-Maximilians-University, GINI/LISA South (Koletzko S, Reinhardt D, Krauss-Etschmann S); Department of Pediatrics, Technical University, GINI/LISA South (Bauer CP, Brockow I, Grübl A, Hoffmann U); IUF-Institut für Umweltmedizinische Forschung at the Heinrich-Heine-University, Düsseldorf (Krämer U, Link E, Klümper C); Centre for Allergy and Environment, Technical University, GINI/LISA South (Behrendt H). LISAplus study group: Helmholtz Zentrum München, German Research Center for Environmental Health, Institute of Epidemiology, GINI/LISA South (Heinrich J, Wichmann HE, Sausenthaler S, Chen CM, Schnappinger M); Department of Pediatrics, Municipal Hospital 'St. Georg', LISA East (Borte M, Diez U), Marien-Hospital GINI/LISA North, Department of Pediatrics, GINI/LISA North (von Berg A, Beckmann C, Groß I); Pediatric Practice, Bad Honnef (Schaaf B); Helmholtz Centre for Environmental Research-UFZ, Department of Environmental Immunology/Core Facility Studies, LISA East (Lehmann I, Bauer M, Gräbsch C, Röder S, Schilde M); University of Leipzig, Institute of Hygiene and Environmental Medicine, LISA East (Herbarth O, Dick C, Magnus J); IUF-Institut für Umweltmedizinische Forschung, Düsseldorf (Krämer U, Link E, Klümper C); Technical University GINI/LISA South, Department of Pediatrics, GINI/LISA South (Bauer CP, Hoffmann U); ZAUM-Center for Allergy and Environment, Technical University, GINI/ LISA South (Behrendt $H$, Grosch J, Martin F).

Contributors EF contributed to the conceptualisation of the project, conducted and interpreted the analyses, prepared and revised the manuscript, approved the final version to be published and agrees to be accountable for this work. IM and JH contributed to the conceptualisation of the project, data collection and the interpretation of the data, critically revised the manuscript, approved the final version to be published and agree to be accountable for this work. AvB, C-PB, DB, SK and DS contributed to data collection and the interpretation of the data, critically revised the manuscript, approved the final version to be published and agree to be accountable for this work. 
Funding The GINIplus study was mainly supported for the first 3 years of the Federal Ministry for Education, Science, Research and Technology (interventional arm) and Helmholtz Zentrum Munich (former GSF) (observational arm). The 4-, 6and 10-year follow-up examinations of the GINIplus study were covered from the respective budgets of the five study centres (Helmholtz Zentrum Munich (former GSF), Marien-Hospital Wesel, LMU Munich, TU Munich and from 6 years onwards also from IUF-Leibniz Research-Institute for Environmental Medicine) and a grant from the Federal Ministry for Environment (IUF, FKZ 20462296). The LISAplus study was mainly supported by grants from the Federal Ministry for Education, Science, Research and Technology and in addition from Helmholtz Zentrum Munich (former GSF), Helmholtz Centre for Environmental Research-UFZ, Leipzig, Marien-Hospital Wesel, Pediatric Practice, Bad Honnef for the first 2 years. The 4-, 6- and 10-year follow-up examinations of the LISAplus study were covered from the respective budgets of the involved partners (Helmholtz Zentrum Munich (former GSF), Helmholtz Centre for Environmental Research—UFZ, Leipzig, Marien-Hospital Wesel, Pediatric Practice, Bad Honnef, IUF-Leibniz-Research Institute for Environmental Medicine) and in addition by a grant from the Federal Ministry for Environment (IUF, FKZ 20462296). The ESCAPE (grant agreement number: 211250) research received funding from the European Community's Seventh Framework Program (FP7/20072011). EF was supported by the Allergy, Genes and Environment Network of Centres of Excellence (AllerGen) (Canadian Allergy and Immune Diseases Advanced Training Initiative) and the Canadian Institutes of Health Research (Sir Frederick Banting and Charles Best Canada Graduate Scholarship and Michael Smith Foreign Study Supplement Award).

\section{Competing interests None.}

Ethics approval Local Ethics Committees approved both studies and written consent was obtained from parents of participants.

Provenance and peer review Not commissioned; externally peer reviewed.

Open Access This is an Open Access article distributed in accordance with the Creative Commons Attribution Non Commercial (CC BY-NC 3.0) license, which permits others to distribute, remix, adapt, build upon this work non-commercially, and license their derivative works on different terms, provided the original work is properly cited and the use is non-commercial. See: http://creativecommons.org/ licenses/by-nc/3.0/

\section{REFERENCES}

1 Donovan GH, Butry DT, Michael YL, et al. The relationship between trees and human health: evidence from the spread of the emerald ash borer. Am J Prev Med 2013;44:139-45.

2 Lee ACK, Maheswaran R. The health benefits of urban green spaces: a review of the evidence. J Public Health 2011;33:212-22.

3 Maas J, Verheij RA, Groenewegen PP, et al. Green space, urbanity, and health: how strong is the relation? J Epidemiol Community Health 2006;60:587-92.
4 Markevych I, Fuertes E, Tiesler CMT, et al. Surrounding greenness and birth weight: results from the GINIplus and LISAplus birth cohorts in Munich. Health Place 2014:26:39-46.

5 Mitchell R, Popham F. Greenspace, urbanity and health: relationships in England. J Epidemiol Community Health 2007;61:681-3.

6 Tzoulas K, Korpela K, Venn S, et al. Promoting ecosystem and human health in urban areas using Green Infrastructure: A literature review. Landsc Urban Plan 2007;81:167-78.

7 Lovasi GS, Quinn JW, Neckerman KM, et al. Children living in areas with more street trees have lower prevalence of asthma. J Epidemiol Community Health 2008;62:647-9.

8 Lovasi GS, O'Neil-Dunne JPM, Lu JWT, et al. Urban tree canopy and asthma, wheeze, rhinitis, and allergic sensitization to tree pollen in a New York City birth cohort. Environ Health Perspect 2013;121:494-500.

9 Strachan DP. Hay fever, hygiene, and household size. BMJ 1989;299:1259-60.

10 Von Hertzen L, Hanski I, Haahtela T. Natural immunity: biodiversity loss and inflammatory diseases are two global megatrends that might be related. EMBO Rep 2011;12:1089-93.

11 Ghiani A, Aina R, Asero R, et al. Ragweed pollen collected along high-traffic roads shows a higher allergenicity than pollen sampled in vegetated areas. Allergy 2012;67:887-94.

12 Fuertes $\mathrm{E}$, Standl M, Cyrys J, et al. A longitudinal analysis of associations between traffic-related air pollution with asthma, allergies and sensitization in the GINIplus and LISAplus birth cohorts. Peer J 2013;1:e193.

13 Weier J, Herring D. Measuring vegetation (NDVI \& EVI) [Internet]. 2000 [cited 2013 Dec 30]. http://earthobservatory.nasa.gov/Features/MeasuringVegetation/printall.php

14 Hanski I, von Hertzen L, Fyhrquist $\mathrm{N}_{\text {, }}$ et al Environmental biodiversity, human microbiota, and allergy are interrelated. Proc Natl Acad Sci 2012;109:8334-9.

15 Beelen R, Hoek G, Vienneau D, et al. Development of NO2 and NOx land use regression models for estimating air pollution exposure in 36 study areas in Europe - The ESCAPE project. Atmos Environ 2013;72:10-23.

16 Cyrys J, Eeftens M, Heinrich J, et al. Variation of NO2 and NOx concentrations between and within 36 European study areas: results from the ESCAPE study. Atmos Environ 2012;62:374-90.

17 Eeftens M, Beelen R, de Hoogh K, et al. Development of land use regression models for PM2.5, PM2.5 absorbance, PM10 and PM coarse in 20 European study areas; results of the ESCAPE project. Environ Sci Technol 2012;46:11195-205.

18 Eeftens M, Tsai M-Y, Ampe C, et al. Spatial variation of PM2.5, PM10, PM2.5 absorbance and PM coarse concentrations between and within 20 European study areas and the relationship with NO2-results of the ESCAPE project. Atmos Environ 2012;62:303-17.

19 Cariñanos P, Casares-Porcel M. Urban green zones and related pollen allergy: a review. Some guidelines for designing spaces with low allergy impact. Landsc Urban Plan 2011;101:205-14.

20 Alcock I, White MP, Wheeler BW, et al. Longitudinal effects on mental health of moving to greener and less green urban areas. Environ Sci Technol 2014:48:1247-55. 


\section{Greenness and allergies: evidence of differential associations in two areas in Germany}

Elaine Fuertes, lana Markevych, Andrea von Berg, Carl-Peter Bauer,

Dietrich Berdel, Sibylle Koletzko, Dorothea Sugiri and Joachim Heinrich

J Epidemiol Community Health 2014 68: 787-790 originally published online May 26, 2014

doi: 10.1136/jech-2014-203903

Updated information and services can be found at:

http://jech.bmj.com/content/68/8/787

These include:

Supplementary

Supplementary material can be found at:

Material

http://jech.bmj.com/content/suppl/2014/05/26/jech-2014-203903.DC1

References

This article cites 19 articles, 7 of which you can access for free at:

http://jech.bmj.com/content/68/8/787\#BIBL

Open Access This is an Open Access article distributed in accordance with the Creative Commons Attribution Non Commercial (CC BY-NC 3.0) license, which permits others to distribute, remix, adapt, build upon this work non-commercially, and license their derivative works on different terms, provided the original work is properly cited and the use is non-commercial. See: http://creativecommons.org/licenses/by-nc/3.0/

Email alerting Receive free email alerts when new articles cite this article. Sign up in the service box at the top right corner of the online article.

Topic
Collections

Articles on similar topics can be found in the following collections

Open access (287)

Air pollution (103)

Environmental issues (205)

\section{Notes}

To request permissions go to:

http://group.bmj.com/group/rights-licensing/permissions

To order reprints go to:

http://journals.bmj.com/cgi/reprintform

To subscribe to BMJ go to:

http://group.bmj.com/subscribe/ 